\title{
Weed discrimination using ultrasonic sensors
}

\author{
D ANDÚJAR*, A ESCOLÀ†, J DORADO* \& C FERNÁNDEZ-QUINTANILLA* \\ *Instituto de Ciencias Agrarias, CSIC, Madrid, Spain, and $\uparrow$ Universitat de Lleida, Lleida, Spain
}

Received 11 March 2011

Revised version accepted 7 June 2011

Subject Editor: Peter Lutman, UK

\section{Summary}

A new approach is described for automatic discrimination between grasses and broad-leaved weeds, based on their heights. An ultrasonic sensor was mounted on the front of a tractor, pointing vertically down in the interrow area, with a control system georeferencing and registering the echoes reflected by the ground or by the various leaf layers. Static measurements were taken at locations with different densities of grasses (Sorghum halepense) and broad-leaved weeds (Xanthium strumarium and Datura spp.). The sensor readings permitted the discrimination of pure stands of grasses (up to $81 \%$ success) and pure stands of broad-leaved weeds (up to $99 \%$ success). Moreover, canonical discriminant analy- sis revealed that the ultrasonic data could separate three groups of assemblages: pure stands of broad-leaved weeds (lower height), pure stands of grasses (higher height) and mixed stands of broad-leaved and grass weeds (medium height). Dynamic measurements confirmed the potential of this system to detect weed infestations. This technique offers significant promise for the development of real-time spatially selective weed control techniques, either as the sole weed detection system or in combination with other detection tools.

Keywords: weed species discrimination, site-specific weed management, wide-row crops, ultrasound detection, patch, sonar.

Andújar D, Escolà A, Dorado J \& Fernández-Quintanilla C (2011). Weed discrimination using ultrasonic sensors. Weed Research 51, 543-547.

\section{Introduction}

Although numerous studies have been conducted in the past to develop ground detection methods to assess weed infestations, none of these methods has yet been introduced commercially. Therefore, there is a need for precise, low-cost sensors that can be incorporated into already available commercial equipment for real-time weed patch spraying.

Optical sensors have been used in the past to map and/or spray weed patches present in fallow sites and in various wide-row crops (Biller, 1998; Andújar et al., 2011). Although these sensors are not able to differentiate weed species from crops, this does not represent a major problem if the sensor is operated only in the interrow area and the infested areas are treated with broad- spectrum contact action herbicides. However, although some of these systems are already commercially available (WeedSeeker ${ }^{\circledR}$, Weed-IT ${ }^{\circledR}$ ), the lack of discrimination power and the relatively high cost of these sensors are serious deterrents to wider acceptance. In recent years, numerous studies have used machine vision techniques to detect and identify plant species (either crops or weeds) based on their shape, colour and texture (Gerhards \& Oebel, 2006; Slaughter et al., 2008). Sonar technologies could also describe weed geometry and discriminate different weed species (Mckerrow \& Harper, 1999). Although these techniques have proved to be possible, they require relatively long computing time and may be costly.

Plant height and biomass are reliable parameters for the assessment of weed stands. Previous studies have 
shown that these parameters can be estimated using ultrasonic sensors (Shibayama et al., 1985; Reusch, 2009). Consequently, we hypothesised that these sensors could also be used for weed detection and discrimination. Standard ultrasonic sensors are robust and relatively cheap, compared with other sensors. However, their performance is affected by the target to be detected, in this case, the canopy structure (Escolà et al., 2011). This study was conducted to assess the use of ultrasonic sensors to detect weeds in the inter-rows of maize, exploring sensor capabilities and limitations to discriminate weed species of different heights.

\section{Materials and methods}

\section{Weed detection system}

Ultrasonic sensors provide an estimation of the distance from the sensor to the first obstacle, generating an echo according to the time-of-flight method. A Pepperl + Fuchs UC2000-30GM-IUR2-V15 ultrasonic sensor (technical characteristics: http://www.pepperl-fuchs.com/ global/en/classid_186.htm?view $=$ productdetails\&prodid $=$ 4221) was mounted on the front of a tractor, pointing vertically downwards to the ground. This sensor has an approximate beam angle of $10^{\circ}$, leading to an effective footprint diameter of $c .0 .30 \mathrm{~m}$ when placed at a height of $0.80 \mathrm{~m}$. The transducer ultrasound frequency is approximately $180 \mathrm{kHz}$ with a sensor resolution of $0.48 \mathrm{~mm}$ when working in full evaluation range (80$2000 \mathrm{~mm}$ ). A deflective shield was installed around the sensor to avoid maize leaves interfering with the readings of inter-row weeds. The response delay of the sensor was set to $195 \mathrm{~ms}$, so that its frequency coincided with the global positioning receiver. Geopositioning was obtained from a differential global positioning system (DGPS) receiver (Hemisphere Crescent R130), with an Omnistar correction signal capable of sub-metre accuracy (about $0.6 \mathrm{~m}$ ), working at $5 \mathrm{~Hz}$ update frequency. The DGPS antenna was located on top of the sensor. Dedicated software was developed using National Instruments LabVIEW graphical language to acquire and process ultrasonic sensor and DGPS receiver data using a compact FieldPoint (National Instruments) device. The program was designed to acquire the output voltage of the sensor and convert it into a distance using an experimental linear regression model equation. System calibration was conducted in a weed-free area in the field to be mapped, to establish the distance from the sensor to the ground in working conditions and save it as the reference distance. After calibration, the height of weeds was estimated by subtracting the actual estimated distance from the reference distance. The program can work in a single (static) measurement mode or in a continuous (dynamic) recording mode; the latter was used along with DGPS co-ordinates to identify and map weed patches in the fields.

\section{Experimental set-up and measurements}

Assessments were conducted in two maize fields located in La Poveda Research Farm (Arganda del Rey, Madrid, Spain). Maize was planted on 8 April with $0.75-\mathrm{m}$ row spacing and a population of 85000 plants $\mathrm{ha}^{-1}$. Weeds were assessed on 6 May (static measurements in fields A and B) and 25 May (static and dynamic measurements in field B) at the maize growth stages $\mathrm{BBCH} 12-14$ and $\mathrm{BBCH}$ 16-18 respectively.

Field A was heavily infested with Sorghum halepense (L.) Pers., Datura ferox L. and Xanthium strumarium L., with only occasional weed-free areas. Field B was mainly infested with $S$. halepense and Datura stramonium L. Weed growth stages at the two sampling dates ranged from $\mathrm{BBCH} 12$ to $\mathrm{BBCH} 18$ for dicotyledonous weeds and between $\mathrm{BBCH} 32$ and BBCH 36 for $S$.halepense. Although the fields had received a pre-emergence treatment with $\mathrm{S}$-metolachlor $\left(1.20 \mathrm{~kg}\right.$ a.i. $\left.\mathrm{ha}^{-1}\right)+$ mesotrione $\quad\left(0.12 \mathrm{~kg}\right.$ a.i. ha $\left.{ }^{-1}\right)$, residual populations of these four species were still abundant. Static measurements were taken at 254 different locations (167 locations on the first date and 87 on the second date), which were selected within both fields with different densities of pure and mixed stands of these species. Locations were chosen to achieve at equitable distribution between weed groups, i.e. with approximately similar numbers of locations for pure stands of $S$. halepense, broad-leaved weeds and mixtures. In some cases, it was necessary to hand-weed the location, to obtain the desired compositions. These static measurements were taken by pointing the sensor at the centre of the sampled area. All readings acquired at the same location within an interval of $5 \mathrm{~s}$ were averaged, and the averaged measured heights and the standard deviations were stored. Immediately after taking ultrasonic readings, average height of the various weed species present was determined using a metre rule. All plants present in a 0.30 -m-diameter circle, coinciding with the sensor footprint, were harvested and taken to the laboratory for biomass (dry weight basis) determination.

To assess the capability of this system for mapping weed infestations, a dynamic study was conducted in field B on 25 May. This field presented an ideal situation for our test, with only two weed species of contrasting heights and marked spatial distribution patterns. Georeferenced points were taken at 0.20 -s intervals, by setting this update frequency in the DGPS receiver. As the tractor was travelling at approximately $1.50 \mathrm{~m} \mathrm{~s}^{-1}$, the 
Table 1 Average heights in $\mathrm{cm}$ (in brackets the range of values) of weed species at two sampling dates

\begin{tabular}{lcl}
\hline & 6 May & 25 May \\
\hline Sorghum halepense & $15.2(8.0-27.0)$ & $32.9(20.0-49.0)$ \\
Datura spp. & $4.6(3.0-6.0)$ & $12.9(8.0-18.0)$ \\
Xanthium strumarium & $6.7(4.0-10.0)$ & $19.0(14.0-22.0)$ \\
\hline
\end{tabular}

distance between points within the same row was approximately $0.30 \mathrm{~m}$, which corresponded with the footprint diameter of the sensor. Thereafter, to verify the dynamic measurements, plant height and biomass were determined at 87 georeferenced sampling points following the same procedure described previously.

\section{Statistical analysis}

Multiple linear regressions were used to identify the most significant parameters (e.g. plant height and weed biomass) that explained the observed variations in ultrasonic readings for each individual species and for various species combinations. After testing the normality of the distribution of two independent variables (distance from the sensor and standard deviation of measurements), a univariate analysis of variance (ANOVA) was performed, to assess the capability of independent variables to discriminate significantly between weed groups. Following this analysis, canonical discriminant analysis (CDA) was used to classify and predict the different compositions of weeds (Kenkel et al., 2002). In the analyses, two cases were considered: (a) the ability of the system to discriminate grasses from broad-leaved weeds and (b) the ability to discriminate three types of situations: (i) grasses (S. halepense), (ii) mixture of grasses and broad-leaved weeds and (iii) broad-leaved weeds [D. ferox, D. stramonium (hereinafter, we will refer to both species as Datura spp.) and $X$. strumarium]. The same analyses were conducted for static and dynamic measurements, although in the latter, no standard deviation values were available. (The continuous assessment assigned a single value to each m co-ordinate.)

\section{Results and discussion}

Weed species considered in this study had contrasting heights, with $S$. halepense being significantly taller at both sampling dates (Table 1). Although heights of

Table 2 Multiple regression analysis between ultrasonic readings and measured height and biomass for weed species (Sorghum halepense, Datura spp. and Xanthium strumarium) and paired species mixtures at two different dates

\begin{tabular}{|c|c|c|c|c|c|c|}
\hline & \multicolumn{3}{|l|}{6 May } & \multicolumn{3}{|l|}{25 May } \\
\hline & & Coefficient* & $P$-value & & Coefficient & $P$-value \\
\hline \multirow[t]{2}{*}{ S. halepense } & Height & & n.s. & Height & $0.68(0.17)$ & $<0.001$ \\
\hline & $\begin{array}{l}\text { Biomass } \\
R^{2}=0.51 \dagger\end{array}$ & $2.29(0.4)$ & $<0.001$ & $\begin{array}{l}\text { Biomass } \\
R^{2}=0.73\end{array}$ & $0.36(0.16)$ & 0.029 \\
\hline \multirow[t]{2}{*}{ Datura spp. } & Height & & n.s. & Height & $0.99(0.30)$ & 0.003 \\
\hline & Biomass & & n.s. & $\begin{array}{l}\text { Biomass } \\
R^{2}=0.70\end{array}$ & $0.33(0.18)$ & 0.075 \\
\hline \multirow[t]{2}{*}{ X. strumarium } & Height & $1.54(0.6)$ & 0.021 & & & \\
\hline & $\begin{array}{l}\text { Biomass } \\
R^{2}=0.37\end{array}$ & & n.s. & & & \\
\hline \multirow{4}{*}{ S. halepense \& Datura spp. } & Height (S. halepense) & $0.73(0.3)$ & 0.010 & Height (S. halepense) & $0.72(0.17)$ & $<0.001$ \\
\hline & Biomass (S. halepense) & $1.51(0.4)$ & 0.002 & Biomass (S. halepense) & & n.s. \\
\hline & Height (Datura spp.) & & n.s. & Height (Datura spp.) & & n.s. \\
\hline & $\begin{array}{l}\text { Biomass (Datura spp.) } \\
R^{2}=0.55\end{array}$ & $3.32(1.3)$ & 0.021 & $\begin{array}{l}\text { Biomass (Datura spp.) } \\
R^{2}=0.40\end{array}$ & & n.s. \\
\hline \multirow[t]{4}{*}{ S. halepense \& X. strumarium } & Height (S. halepense) & & n.s. & & & \\
\hline & Biomass (S. halepense) & $2.38(1.0)$ & 0.026 & & & \\
\hline & Height ( $X$. strumarium) & & n.s. & & & \\
\hline & $\begin{array}{l}\text { Biomass }(X . \text { strumarium }) \\
R^{2}=0.20\end{array}$ & & n.s. & & & \\
\hline \multirow[t]{4}{*}{ Datura spp. \& X. strumarium } & Height (Datura spp.) & & n.s. & & & \\
\hline & Biomass (Datura spp.) & & n.s. & & & \\
\hline & Height ( $X$. strumarium) & & n.s. & & & \\
\hline & Biomass ( $X$. strumarium) & & n.s. & & & \\
\hline
\end{tabular}

Results of the static measurements. Xanthium strumarium was not found in the sampling of the field B on 25 May.

$P$-value, significance level; n.s., not significant at the $5 \%$ level.

* Regression coefficients with standard errors in parenthesis.

$\dagger R^{2}$ of the model, including dependent (ultrasonic reading) and independent variables (height and biomass). 
Table 3 Classification results showing the percentages of original grouped cases correctly classified into two or three weed type groups based on ultrasonic readings

\begin{tabular}{|c|c|c|c|c|c|}
\hline \multirow[b]{3}{*}{$\begin{array}{l}\text { Measurement } \\
\text { (date) }\end{array}$} & \multicolumn{5}{|c|}{ Predicted group membership } \\
\hline & \multicolumn{2}{|l|}{ Two groups } & \multicolumn{3}{|l|}{ Three groups } \\
\hline & $\begin{array}{c}\text { Pure stands } \\
\text { of grasses }\end{array}$ & $\begin{array}{l}\text { Pure stands } \\
\text { of broad leaves }\end{array}$ & $\begin{array}{c}\text { Pure stands } \\
\text { of grasses }\end{array}$ & $\begin{array}{l}\text { Mixed } \\
\text { stands }\end{array}$ & $\begin{array}{l}\text { Pure stands } \\
\text { of broad leaves }\end{array}$ \\
\hline Static (6 May) & 81.1 & 98.5 & $57.5\left(17.5^{*}\right)$ & $38.2\left(20.0^{*}\right)$ & $97.0(0.0 \dagger)$ \\
\hline Static (25 May) & 79.6 & 97.0 & $71.4\left(7.1^{*}\right)$ & $46.2\left(26.9^{*}\right)$ & $93.9(0.0 \dagger)$ \\
\hline Dynamic (25 May) & 77.8 & 97.0 & $71.4\left(10.7^{*}\right)$ & $53.8\left(23.1^{*}\right)$ & $87.9(0.0 \dagger)$ \\
\hline
\end{tabular}

Measurements were taken on two different dates with both static and dynamic mode.

*Percentage of cases misclassified as 'pure stands of broad leaves'.

$\dagger$ Percentage of cases misclassified as 'pure stands of grasses'.

Datura spp. and $X$. strumarium were relatively uniform, a wider range of values was obtained for $S$. halepense.

Static measurements showed the potential of this technique to assess plant height and biomass. Readings taken in pure stands of $S$. halepense were well correlated with the biomass of this weed at both sampling dates and with plant height at the later date (Table 2). In the case of Datura spp., correlations were good at the second date, but not at the first one. Correlations of $X$. strumarium height and biomass with ultrasonic readings were poor at the 6th May evaluation. (This species was not present in field $\mathrm{B}$, used for the dynamic evaluation of 25 May.) In species mixtures, ultrasonic readings were good predictors of $S$. halepense height and/or biomass in most cases, but they did not show good relationships with the parameters of both broadleaved weeds. The baseline to assess the various plant situations was recorded on bare soil, where ultrasonic readings provided a fairly accurate measure of the distance between sensor and ground, despite small fluctuations owing to soil irregularities and the position of the vehicle.

ANOVA showed that there were significant differences between weed groups in both static and dynamic measurements (data not shown). Subsequently, CDA provided relatively good results (Table 3 ) when weeds were classified into two predefined groups (grasses and broad-leaved weeds). Indeed, the proportion of cases classified correctly for pure stands of grasses was 80$81 \%$. All misclassified cases were associated with very low $S$. halepense biomass. In addition, 97-99\% of the cases of pure stands of broad-leaved weeds were classified correctly. When weeds were classified into three predefined groups, (grasses, broad-leaved and mixed stands of both weed types), CDA resulted in poorer predictions. At the first sampling date, pure stands of grasses and broad-leaved weeds were correctly classified into $58 \%$ and $97 \%$ of the cases respectively. These predictions improved at the second sampling, with $71 \%$ of the cases being well classified as grasses and $94 \%$
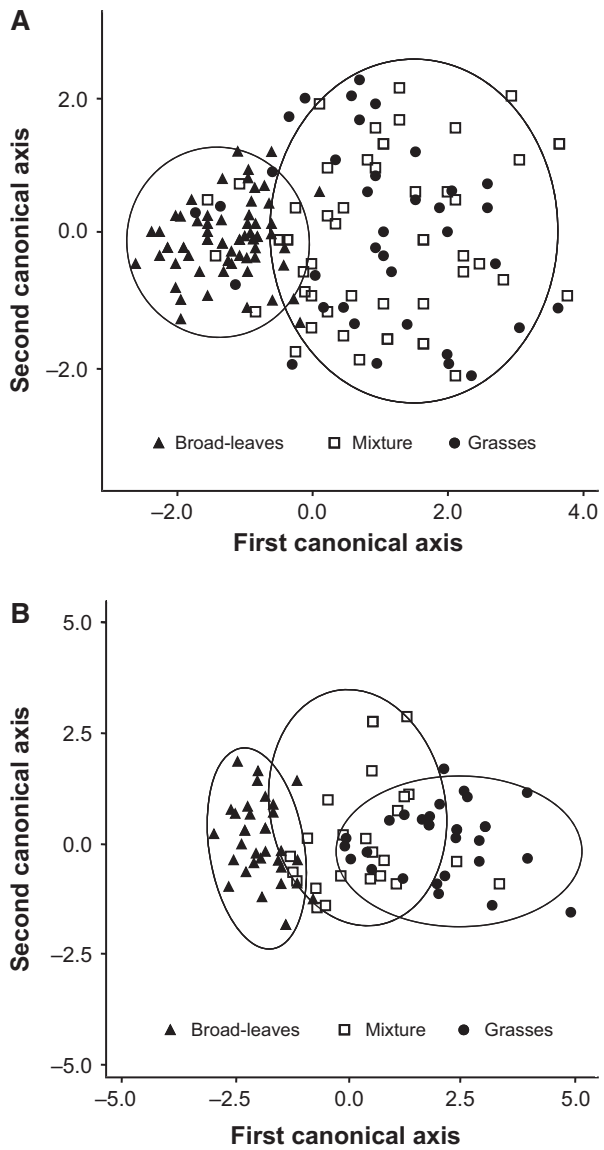

Fig. 1 Canonical discriminant function plot of ultrasonic readings in three groups representing pure stand of grasses, pure stand of broad-leaved and mixed weed stands. (A) Sampling on 6 May; (B) sampling on 25 May.

as broad-leaved weeds. The presence of mixed stands was predicted in $38-46 \%$ of the cases, with better results at the second sampling date. In spite of the better discrimination obtained at the later stage, it is not advisable to delay weed detection and herbicide application until this date, because of the higher risks of poor weed control and higher yield losses. Further work 


\section{Length $(m)$}

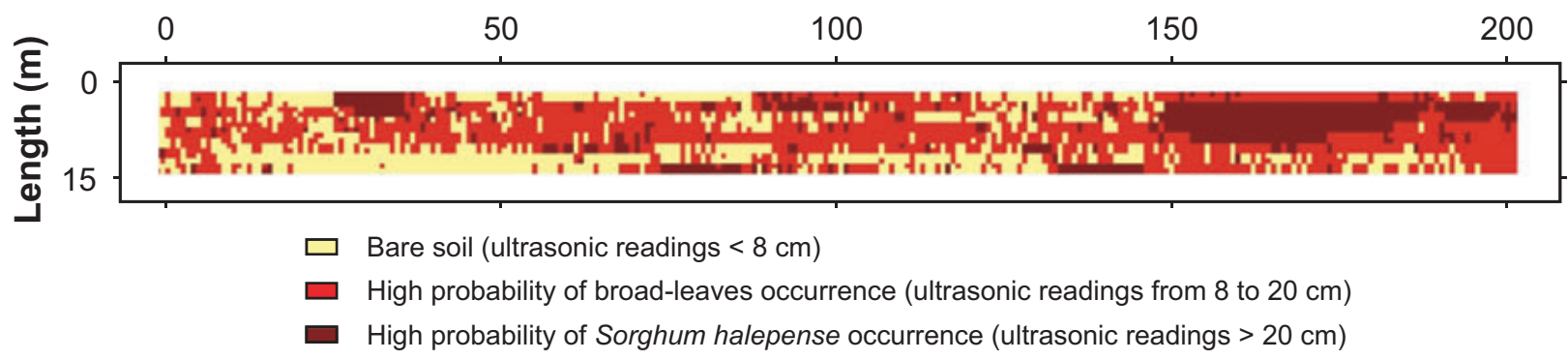

Fig. 2 Weed map derived from the data collected in the dynamic assessment on 25 May in field B.

should focus on improving weed discrimination at early growth stages.

The canonical discriminant function plot (Fig. 1) identifies differences between groups based on sampling date. At the earlier date, the centroid of the pure broadleaved group separates from the centroids of the other two groups, but some overlapping was observed between the position of the pure stands of grasses and mixed stands (Fig. 1A). In contrast, at the second sampling date, the centroids of the three weed groups were clearly separated by the first canonical discriminant function which differentiated grasses, broad leaves and mixed stands (Fig. 1B).

Dynamic measurements confirmed the capability of this system for weed detection and weed mapping (Fig. 2). When weeds were classified into two groups, pure stands of grasses and broad-leaved weeds were correctly classified into $78 \%$ and $97 \%$ of the cases respectively (Table 3 ). When weeds were classified into three groups, the cases well classified were $71 \%, 88 \%$ and $54 \%$ for grasses, broad-leaved weeds and mixed stands respectively.

It seems that the tall, erect $S$. halepense plant canopies produced signals clearly different from those of Datura spp. or X. strumarium canopies, which were much lower and with horizontal leaves. This power of discrimination represents a clear advantage over optoelectronic methods that can only provide an estimate of the presence/absence of weeds on the ground (Andújar et al., 2011). Although this approach did not permit the differentiation of species with similar height characteristics (e.g. Datura spp. from X. strumarium), it may be adequate for deciding on the use of grass or broad-leaved herbicides in situations where these two types of weeds have marked height differences. The map generated in Fig. 2 suggests that spatially selective treatment might be feasible for $S$. halepense, as well as for both broad-leaved weeds considered as a single target.

The low cost, robustness and relatively fast reaction of ultrasonic sensors make them a promising tool to be integrated into real-time patch sprayers in situations where crops are grown in wide rows and the major weed species have clearly distinct heights. Additionally, data retrieved by these sensors may reveal useful information on weed biomass and canopy structure. However, further work is needed to explore these possibilities.

\section{Acknowledgements}

This research was funded by the Spanish CICyT (project AGL 2008-04670-C03).

\section{References}

Andújar D, Ribeiro A, Fernández-Quintanilla C \& Dorado J (2011) Accuracy and feasibility of optoelectronic sensors for weed mapping in row crops. Sensors 11, 23042318.

BiLLER RH (1998) Reduced input of herbicides by use of optoelectronic sensors. Journal of Agricultural Engineering Research 71, 357-362.

Escolà A, Planas S, Rosell JR et al. (2011) Performance of an ultrasonic ranging sensor in apple tree canopies. Sensors 11, 2459-2477.

Gerhards R \& Oebel H (2006) Practical experiences with a system for site-specific weed control in arable crops using real-time image analysis and GPS-controlled patch spraying. Weed Research 46, 185-193.

Kenkel NC, Derksen DA, Thomas AG \& Watson PR (2002) Review: multivariate analysis in weed science research. Weed Science 50, 281-292.

MCKerrow PJ \& HARPER NL (1999) Recognising leafy plants with in-air sonar. Sensor Review 19, 202-206.

Reusch S (2009) Use of ultrasonic transducers for on-line biomass estimation in winter wheat. In: Precision Agriculture '09 (eds EJ van Henten, D Goense \& C Lokhorst), 169175. Wageningen Academic Publishers, Wageningen, The Netherlands.

Shibayama M, Akiyama T \& Munakata K (1985) A portable field ultrasonic sensor for crop canopy characterization. Remote Sensing of Environment 18, 269-279.

Slaughter DC, Giles DK \& Downey D (2008) Autonomous robotic weed control systems: a review. Computers and Electronics in Agriculture 61, 63-78. 